\title{
Jogo Digital Educacional como Ferramenta de Auxílio na Conscientização e Prevenção às Drogas
}

\section{Igor Pereira de Almeida ${ }^{1}$, Joselice Ferreira Lima ${ }^{2}$,Luciana Oliveira Melo ${ }^{3}$, Edlâine Rodrigues Nunes ${ }^{4}$, Wilian Renan Rodrigues Gonçalves ${ }^{5}$, Danilo Magalhães Nunes ${ }^{6}$}

Abstract. Given the current interests of a generation of connected youth and teens, Generation $Z$ has a great ally in drug prevention as educational digital games, since one of the main interests of this generation is games. It is feasible that the implementation of technological and educational solutions in the process of preventing the use of licit and / or illicit drugs, have as main objective to demonstrate the educational digital game Exterminating Drugs which portrays such daily situation.

\section{Introdução}

A geração atual de jovens é conhecida como geração $\mathrm{Z}$, pois já nasceu antenada com a tecnologia que vem transformando a maneira de pensar, consumir e aprender. Casas (2019) diz o que importa para essa geração é encontrar meios de comunicação que faz sentidos para eles. Considera-se que os ambiente escolar é um espaço propício para a interação e socialização entre os indivíduos que propicia a formação de grupos.

Em Casas (2019), aponta que essa geração gosta de três assuntos: música, game e smartphones, considerando o smartphone o portal de conexão com o mundo, enquanto os jogos já fazem parte de seu cotidiano. Damasceno et al (2016) defende que é possível notar nos adolescentes uma desmotivação quanto às abordagens preventivas tradicionais. Utilizar jogos digitais educacionais na temática sobre drogas pode ser uma alternativa viável, pois as dificuldades atuais em conscientizar e prevenir o uso de drogas se encontram na desmotivação e desinteresse do público-alvo em compreender de forma clara e abrangente os perigos por trás de seu uso. Alcântara et al. (2015) comenta que álcool e o tabaco são as drogas mais consumidas no Brasil e são drogas que são legalizadas em todo território, consideradas lícitas, mas o seu consumo é proibido até a maioridade. Enquanto as drogas ilícitas são as não autorizadas, a Maconha e o Crack.

O objetivo desse artigo é apresentar o jogo digital educacional Exterminando Drogas (2018) como auxílio na conscientização e prevenção à drogas lícitas e ilícitas, visto que existe uma carência de materiais interativos sobre a temática. A relevância desse artigo está em apresentar uma ferramenta lúdica e de fácil compreensão à jovens e adolescentes, compondo o jogo em quatro fases: Álcool, Tabaco, Maconha e Crack.

\section{Materiais e Métodos}

A metodologia adotada nesta pesquisa é aplicada, bibliográfica e quantitativa Gerhardt e Silveira (2009). A seleção das drogas incluída no jogo aconteceu baseado na literatura verificada e em questionário aplicado a educadores sobre o tema drogas.

O Jogo Exterminando Drogas foi desenvolvido utilizando Unity 5, em sua versão gratuita. $\mathrm{O}$ jogo foi dividido em quatro fases, onde na primeira fase é tratado a temática sobre Álcool; na segunda o Tabaco; na terceira fase a Maconha, demonstrando que 
VIII Congresso Brasileiro de Informática na Educação (CBIE 2019)

Anais do VIII Workshop de Desafios da Computação aplicada à Educação (DesafIE 2019)

pessoas próximas a esses jovens e adolescentes podem fazer o seu uso e ressalta a importância do apoio de amigos e familiares, na quarta fase o Crack e leva informações sobre os diferentes tipos de drogas.

\section{Resultados e Discussões}

$\mathrm{Na}$ validação do jogo foi aplicado um questionário de dez questões pontuais aos profissionais do Centro de Atenção Psicossocial (CAPS), Centro de Referência de Assistência Social (CRAS) de Januária e aos instrutores do Programa Educacional de Resistência às Drogas (PROERD) do $30^{\circ}$ Batalhão de Polícia Militar de Januária, o qual foi respondido por 30 profissionais que atuam na área do público-alvo e com 10 alunos na faixa etária de 07 a 11 anos da escola Municipal Santa Rita, Januária - Minas Gerais.

A maioria das perguntas buscou analisar os aspectos de um jogo digital educacional bordados por Novak (2010), esses aspectos são: narrativa, personagens, jogabilidade, níveis e interface. Algumas questões foram respondidas de forma unânime quanto a relevância do jogo, onde $100 \%$ dos profissionais o consideram importantíssimo e $94 \%$ dos alunos tiveram essa percepção, gerando resultado satisfatório. Enfim, fica evidente que a utilização de jogos digitais educacionais para auxiliar no ensino e prevenção às drogas é indicado entre os profissionais que atuam na área e os alunos de uma Escola.

\section{Considerações Finais}

Tendo em vista as dificuldades encontradas pelos jovens e adolescentes, é necessário a promoção de atitudes, ferramentas e movimentos que proporcionem ampla compreensão e conhecimento sobre a temática, alertando-os sobre os perigos que estão por trás do uso de drogas, uma vez que ele pode se tornar um vício.

A importância da adoção de jogos digitais educacionais no processo de conscientização e prevenção ao uso de drogas está em utilizar de recursos que sejam atrativos e estimuladores, isto é, capturar a atenção dos adolescentes e jovens que estão antenados com as inovações tecnológicas. Assim, utilizar jogos em campanhas educativas nas escolas permitem que tais ferramentas auxiliem no ensino da temática de forma simples, clara, dinâmica e divertida.Concorrer com jogos de grande escala e com objetivos voltados para o entretenimento, torna o desafio ainda mais complexo. Portanto, para se superar os desafios encontrados na promoção da conscientização e prevenção às drogas deve-se investir no processo educacional visando conhecer os medos, desejos e as aspirações da Geração Z, observando o seu crescente aumento e mudança no modo de pensar e agir diante da grande massa de informação atual.

\section{Referências Bibliográficas}

Alcântara, J.M., Medeiros F.P., Costa, G.Q., Silva L.C.M., Santos, L.A., \& Araújo, K.M. (2015). Estudo e prevenção ao uso de drogas legais e ilegais na Escola Estadual do Ensino Médio Ernesto Penafort, Manaus, Amazonas, Brasil.

Casas, G. (2019). Família, futuro e diversão: conheça as portas de acesso para a Geração Z.

Damasceno, E. F., Nardi, P. A., Silva, A. K. A., Fernando, L., Lopes, B., \& Fernandes, A. M. (2016). Um serious game como estratégia na promoção da saúde no combate ao uso de drogas. J Bras Tele, 4(2), 237-245.

Exterminando Drogas (2018). Disponivel em: sharegames.itch.io/exterminando-drogas 
VIII Congresso Brasileiro de Informática na Educação (CBIE 2019)

Anais do VIII Workshop de Desafios da Computação aplicada à Educação (DesafIE 2019)

Gerhardt, T. E., \& Silveira, D.T. (2009). Métodos de pesquisa.

Novak, J. (2010). Desenvolvimento de Games (Tradução da 2a Edição Norte-Americana). Cengage Learning, São Paulo - SP, Brasil. [GS Search]. 